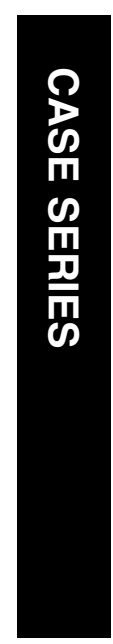

\section{Virus-induced chalazion}

\begin{abstract}
Purpose To investigate a viral etiology in certain chalazia.

Methods A prospective study over 7.5 years of all newly presenting chalazia associated with diffuse follicular conjunctivitis but without any other aetiological factors. Patients were investigated for ocular or systemic infections by history, physical exam, slit-lamp exam, and/or histology of conjunctival biopsy (including transmission electron microscopy). Results A total of 27 patients developed follicular conjunctivitis without meibomian gland dysfunction, blepharitis, or sexually transmitted diseases. Evidence for a viral aetiology included: recent systemic viral illness (15/27), recent contact with subjects with chalazia or follicular conjunctivitis (5/27), preauricular lymphadenopathy (4/27), viral corneal disease $(4 / 27)$, or viral particles by ultrastructure (4/4).

Conclusions Chalazia may be associated with viral conjunctivitis. Intralesional corticosteroids should be considered with great caution for viral-induced chalazia. Eye (2006) 20, 242-246. doi:10.1038/sj.eye. 6701816; published online 4 March 2005
\end{abstract}

${ }^{1}$ Department of Ophthalmology, American University of Beirut, Beirut, Lebanon

${ }^{2}$ National Eye Institute, National Institutes of Health, Bethesda, MD, USA

${ }^{3}$ Department of Internal Medicine, American University of Beirut, Beirut, Lebanon

Correspondence: AM Mansour, Department of Ophthalmology, American University of Beirut, Beirut, Lebanon Tel.: + 9611348543 ; Fax: + 9611744464 . E-mail: dr.ahmad@ cyberia.net.lb

Received: 25 July 2004 Accepted: 1 November 2004

Published online: 4 March 2005
Keywords: chalazion; meibomian gland; viral conjunctivitis

\section{Introduction}

Chalazia represent subacute granulomatous inflammation caused by retention of tarsal gland secretions. ${ }^{1-10}$ Chalazia are associated with meibomian gland dysfunction, chronic blepharitis, or seborrhoeic dermatitis. Bacteria are well implicated in the pathogenesis of chalazia. ${ }^{1,8-10}$ We present a series of patients who developed chalazia following viral conjunctivitis.

\section{Materials and methods}

A prospective study of patients with first-time chalazia and diffuse follicular conjunctivitis was
AM Mansour ${ }^{1}$, C-C Chan², MA Crawford², ZA Tabbarah³ ${ }^{3}$ D Shen², WF Haddad' ${ }^{1}$, I Salti ${ }^{1}$ and NG Ghazi'

conducted in a private clinic setting (AMM) over a period of 7.5 years (January 1996-June 2003). Subjects with meibomian gland dysfunction, blepharitis, acne rosacea, seborrhoeic dermatitis, past family history of chalazia, contact lens usage, past eyelid surgery, and sexually transmitted diseases were excluded. History of previous ocular viral disease was solicited. All patients underwent slit-lamp examination of the eyelid margins and cornea. Preauricular lymph nodes were

palpated. Six patients consented for a biopsy of the palpebral conjunctiva overlying the chalazion. Four specimens were available and submitted in formalin for histopathology to the National Eye Institute in the USA (two specimens were lost in the mail).

\section{Results}

Totally, 27 patients consisted of 18 female and nine male cases with a median age of 32 years (4-75 years) (Table 1). Follicular conjunctivitis was bilateral in 10 patients, unilateral in one patient, and the laterality was not recorded in 16 patients. Chalazia were preceded within 1 week by systemic viral infections: upper respiratory tract infection (13), viral gastroenteritis (one), and viral otitis interna (one). Four patients had preauricular lymphadenopathy. Four patients had viral keratitis clinically: herpes simplex virus in two subjects, Epstein-Barr virus and adenovirus in one subject each.

Five patients had contact with a patient with either chalazion or follicular conjunctivitis. Case 1 had chalazion and follicular conjunctivitis. Within a week, her mother (Case 2), brother (not examined), one sister (Case 3), and her twin sister (not examined) also developed chalazia. Case 20 developed chalazia 3 days following an upper respiratory tract infection. He had persistent follicular conjunctivitis and chalazia for 4 months. His mother (Case 21) developed a chalazion with follicular conjunctivitis 4 weeks after her son's initial symptoms. Case 4, a female teacher, developed a chalazion after 
Table 1 Clinical characteristics of 27 consecutive patients with chalazia and follicular conjunctivitis

\begin{tabular}{|c|c|c|c|c|c|c|c|c|c|}
\hline No. & $\begin{array}{l}\text { Age } \\
\text { (years) }\end{array}$ & Sex & Contact & URTI & Nodes & Site & Multiple & Recurrent & Duration \\
\hline 1 & 18 & Female & Yes & No & No & LUL & No & No & $\begin{array}{l}\text { NA (brother, twin sister, and Cases 2, and } \\
3 \text { had chalazion) }\end{array}$ \\
\hline 2 & 42 & Female & Yes & No & No & $\begin{array}{l}\text { LUL } \\
\text { RUL }\end{array}$ & Yes & Yes & NA (mother of Case 1) \\
\hline 3 & 19 & Female & Yes & No & No & LUL & No & No & NA (sister of Case 1) \\
\hline 4 & 28 & Female & Yes & No & No & LUL & No & No & $\begin{array}{l}3 \text { months (surgical excision) (She kissed a child } \\
\text { with chalazion) }\end{array}$ \\
\hline 5 & 22 & Female & No & Yes & No & RUL & No & Yes & NA \\
\hline 6 & 27 & Male & No & No & No & RLL & No & No & NA \\
\hline 7 & 4 & Male & No & No & No & LUL & No & No & 2 weeks \\
\hline \multirow[t]{2}{*}{8} & 51 & Female & No & Yes & No & RUL & Yes & Yes & $\begin{array}{l}6 \text { months (recurrent viral conjunctivitis } \\
1.5 \text { and } 4 \text { years after chalazion; recurrent } \\
\text { oral aphtous ulcers) }\end{array}$ \\
\hline & & & & & & $\begin{array}{l}\text { RLL } \\
\text { LLL }\end{array}$ & & & \\
\hline 9 & 33 & Male & No & No & No & RUL & No & No & 2 months \\
\hline 10 & 13 & Female & No & Yes & No & LLL & No & No & 2 weeks \\
\hline 11 & 23 & Female & No & No & No & LUL & No & Yes & NA (recurrent adenoviral conjunctivitis) \\
\hline 12 & 23 & Female & No & No & Yes & LLL & No & No & NA \\
\hline 13 & 40 & Male & No & Yes & Yes & RUL & No & No & 2 weeks \\
\hline 14 & 75 & Female & No & No & No & LLL & No & No & 8 months (Epstein-Barr virus nummular corneal scars) \\
\hline 15 & 34 & Female & No & Yes & No & LUL & No & No & 3 months (surgical excision) \\
\hline 16 & 16 & Female & No & Yes & No & LUL & No & No & 1 year \\
\hline 17 & 44 & Male & No & Yes & No & LLL & No & No & 1 week \\
\hline 18 & 31 & Male & No & Yes & No & LLL & No & No & 3 months (biopsy lost in mail) \\
\hline 19 & 55 & Female & No & No & No & LLL & No & No & $\begin{array}{l}1 \text { month; chronic conjunctivitis; disciform } \\
\text { keratitis } 14 \text { months later } \\
\text { (biopsy positive for virus) }\end{array}$ \\
\hline 20 & 34 & Male & Yes & Yes & No & $\begin{array}{l}\text { RUL } \\
\text { LUL }\end{array}$ & Yes & No & 6 months (son of Case 21) \\
\hline 21 & 65 & Female & Yes & No & No & RUL & No & Yes & NA \\
\hline 22 & 22 & Female & No & Yes & Yes & RUL & No & No & 2 months \\
\hline 23 & 62 & Female & No & Yes & No & RUL & No & No & 1 week (biopsy lost in mail) \\
\hline 24 & 45 & Male & No & No & No & $\begin{array}{l}\text { RUL } \\
\text { LUL } \\
\text { LLL } \\
\text { RLL }\end{array}$ & Yes & No & 5 months (biopsy positive for virus) \\
\hline 25 & 13 & Female & No & No & No & LLL & No & No & $\begin{array}{l}1 \text { week (mother had } 5 \text { days prior viral conjunctivitis } \\
\text { and sinusitis) (biopsy positive for virus) }\end{array}$ \\
\hline 26 & 48 & Male & No & Yes & Yes & LLL & No & No & $\begin{array}{l}1 \text { week (disciform keratitis in right eye) } \\
\text { (biopsy positive for virus) }\end{array}$ \\
\hline 27 & 41 & Female & No & Yes & No & LUL & No & No & $\mathrm{NA}$ \\
\hline
\end{tabular}

$\mathrm{N}=$ number; Contact $=$ contact with a patient with chalazion; URTI = upper respiratory tract infection, or viral diarrhoea, or viral otitis; Nodes = preauricular lymphadenopathy; chalazia are characterized by their site, multiplicity, recurrence, and duration; Site = RUL right upper eyelid; $\mathrm{RLL}=$ right lower eyelid; $\mathrm{LUL}=$ left upper eyelid; $\mathrm{LLL}=$ left lower eyelid; $\mathrm{NA}=$ not assessed.

kissing a kindergarten student with chalazion. In addition, a girl (Case 25) had follicular conjunctivitis with a chalazion, 5 days after her mother developed follicular conjunctivitis accompanied by viral sinusitis.

The eyelids affected were as follows: right upper (10) (Figure 1), right lower (three), left upper (11), and left lower (10). Four patients had multiple chalazia. Five patients had recurrent chalazia in the same location. The duration of the chalazia was analysed. Nine patients were lost to follow-up. Two patients had chalazion excision with no recurrence up to 3 months of follow-up. In 17 patients, the chalazion persisted for less than 1 month (eight), 2 months (two), 5 months (one), 6 months (two), 8 months (two), and 1 year (two). The treatment received (before and after presentation to our clinic) included a large variety of topical antibacterial preparations in combination with oral antibiotics or topical antiviral therapy. Cases 24 and 26 underwent biopsy of the central palpebral portion of the chalazion, while Cases 19 and 25 had biopsy of the peripheral 


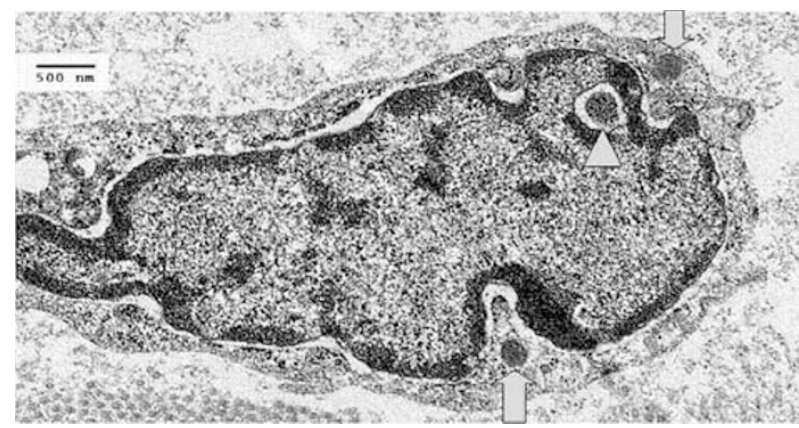

Figure 1 Case 19: Transmission electron micrograph showing dense inclusion bodies (arrowhead), 200-300 $\mathrm{nm}$ in diameter located inside the nucleus. Free enveloped virions (arrows), $250-500 \mathrm{~nm}$ in diameter, are present in the cytoplasmic matrix.

palpebral portion of the chalazion. All four cases demonstrated viral particles by ultrastructure.

\section{Clinical pathological findings}

Case 19

A 55-year-old woman complained of a left lower lid growth accompanied with eye redness and discomfort of 1 week duration. Examination revealed follicular conjunctivitis and chalazion of the left lower eyelid. Biopsy of the adjacent palpebral conjunctiva was obtained. At 14 months after presentation, the chalazion had resolved with persistent redness of the left eye. The left eye had disciform corneal scar, decreased corneal sensation, decreased tear secretion, and minimal follicular conjunctivitis. The clinical impression was herpetic keratoconjunctivitis.

Microscopically, the palpebral conjunctiva consisted of a dense inflammatory cell infiltrate composed of both $\mathrm{T}$ and $\mathrm{B}$ lymphocytes, plasma cells, and macrophages in the substantia propria. Focal inflammatory infiltration was also noted in the epithelium. Transmission electron micrographs showed many viral particles inspissated into large dense inclusion bodies $200-300 \mathrm{~nm}$ in diameter. In their passage through the nuclear membrane, the viral particles acquired an outer envelope with 8-10-nm-long projections. Free enveloped virions, $250-500 \mathrm{~nm}$ in diameter, were present in the cytoplasmic matrix (Figure 1). Both intranuclear and intracytoplasmic inclusions were consistent with herpes viral particles.

\section{Case 24}

This 45-year-old man developed red eyes, similar to his wife's condition. He had bilateral follicular conjunctivitis, as well as chalazia of the right upper, left upper, and left lower eyelids (Figure 2). Biopsy of the palpebral portion

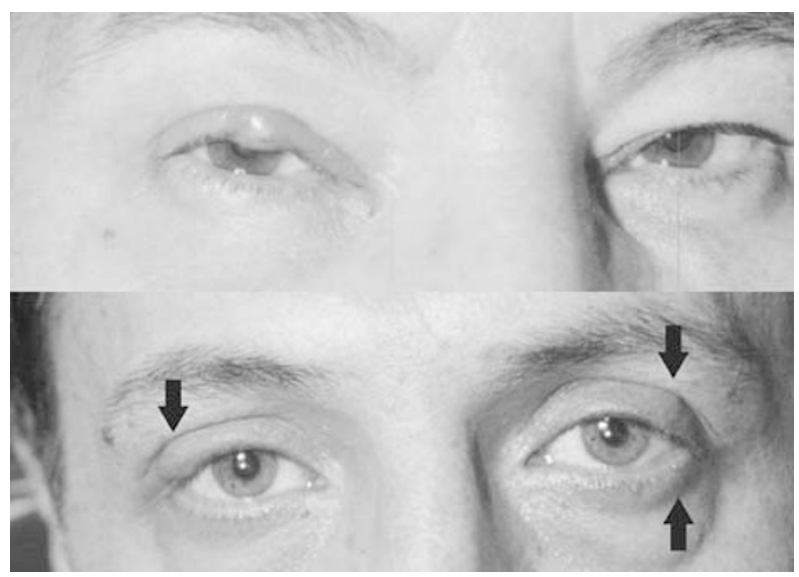

Figure 2 (Top) Case 23: Chalazion of right upper eyelid. (Bottom) Case 24: Chalazia of right upper eyelid, left upper eyelid and left lower eyelid (arrows).

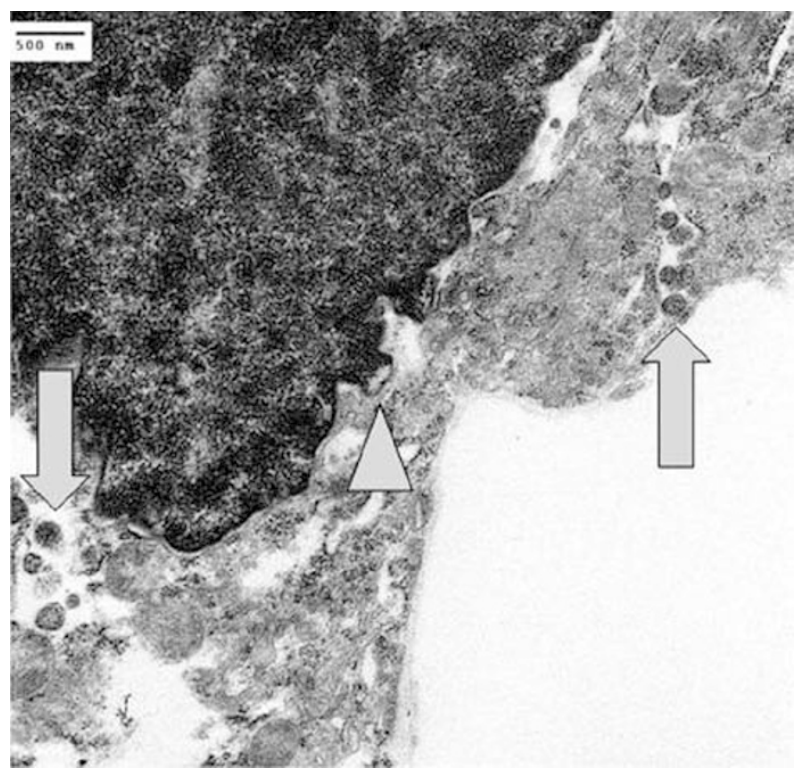

Figure 3 Case 24: Transmission electron micrograph showing virus particles, some with nucleocapsids in the nucleus and enveloped particles, and some with dense core (arrows), sized $120-200 \mathrm{~nm}$, in the cytoplasm and budding out the nuclear membrane (arrowhead).

of the chalazion revealed aggregates of densely packed chronic inflammatory cells, mainly $\mathrm{T}$ lymphocytes, beneath and infiltrating the conjunctival epithelial cells. Granulation and lipid droplets were also present. Transmission electron micrographs disclosed degenerative cells. Several DNA virus particles, some with nucleocapsids in the nucleus and enveloped particles, and some with dense core, sized $120-200 \mathrm{~nm}$, were identified in the cytoplasm and budding out the nuclear membrane (Figure 3). 
Case 25

This 13-year-old girl was followed for the past 4 years for myopia. She complained of a left lower lid mass of 1-day duration. Examination revealed follicular conjunctivitis and a chalazion. At 5 days earlier, her mother had follicular conjunctivitis and viral sinusitis. Biopsy of the palpebral conjunctiva from the periphery of the chalazion revealed aggregates of subacute inflammatory cells, necrotic material, and clusters of Gram-positive short rods. Transmission electron micrographs disclosed many intranuclear and cytoplasmic viral particles (Figure 4), bacilli with rigid cellular wall, and degenerated cells (inflammatory, adipose, and epithelial cells).

\section{Case 26}

This 48-year-old pilot presented following an upper respiratory tract infection with red eyes and was found to have follicular conjunctivitis with preauricular lymphadenopathy. After 4 years, the right eye developed dendritic keratitis. At 9 years after initial presentation, he developed a lower eyelid mass following an episode of upper respiratory tract infection. Examination revealed disciform corneal scar in the right eye, follicular conjunctivitis in the left eye, chalazion of the left lower eyelid, and tender left preauricular lymph nodes. Biopsy of the tarsal side of the chalazion was performed. Bacterial cultures of chalazion contents were negative. Microscopic examination disclosed many lymphocytes,

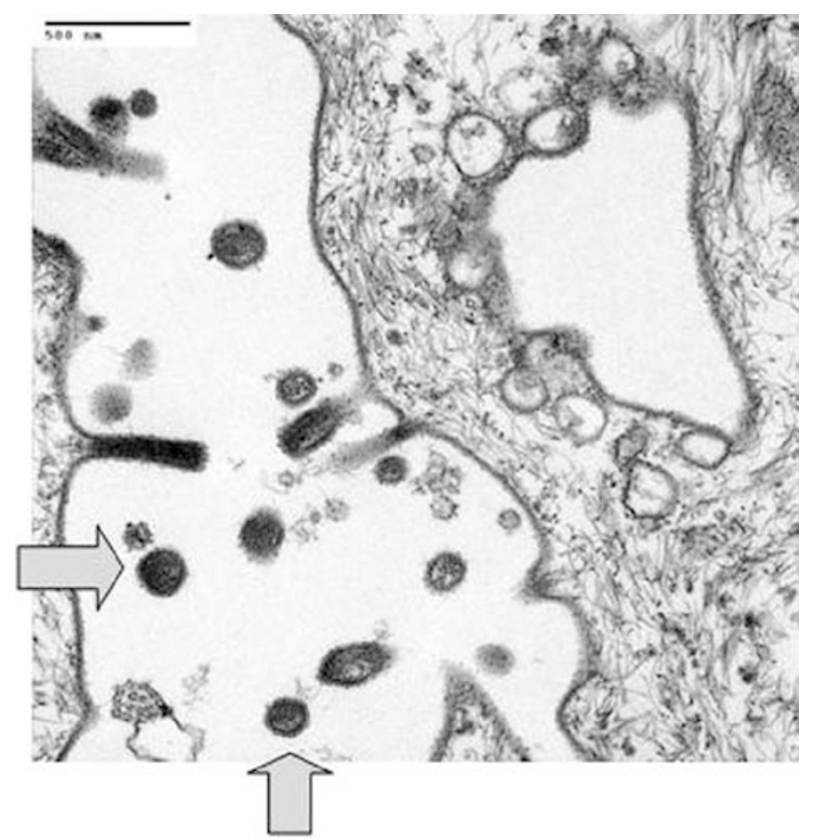

Figure 4 Case 25: Transmission electron micrograph showing intracytoplasmic virions (arrows). macrophages, few polymorphic neutrophils, and lipid drop out material. Gram stain was negative for bacteria. Many granular virus particles were present by ultrastructure in the nuclei. Nucleocapsids and enveloped particles were present in the cytoplasm and plasma membrane (Figure 5).

\section{Discussion}

Meibomian glands consist of holocrine $e^{4,6}$ branching tubuloalveolar modified sebaceous glands, unconnected with hair or erector pili muscle, and arranged vertically throughout the tarsal plate. Meibum-secreting acini project via valve-like structures ${ }^{6}$ into a central canal that opens in front of the mucocutaneous junction of the eyelid margin as a very small orifice. The canal is composed of four layers of cells rising to six layers at the orifice. Meibum is delivered by secretion supplemented by the muscular action of each blink. ${ }^{1}$ Since the palpebral conjunctiva extends all the way to the orifices of the meibomian glands at the lid margin, it is easy to picture how a viral conjunctivitis could clog the tiny orifices by oedema and desquamation. Alternatively, specific viruses might infect meibomian glands leading to altered lipid secretion, change in bacterial flora, ${ }^{10}$ or excessive desquamation of the central meibomian canal.

The present cases may constitute a coincidence between a viral infection and occurrence of chalazia. A subclinical meibomian gland dysfunction could be

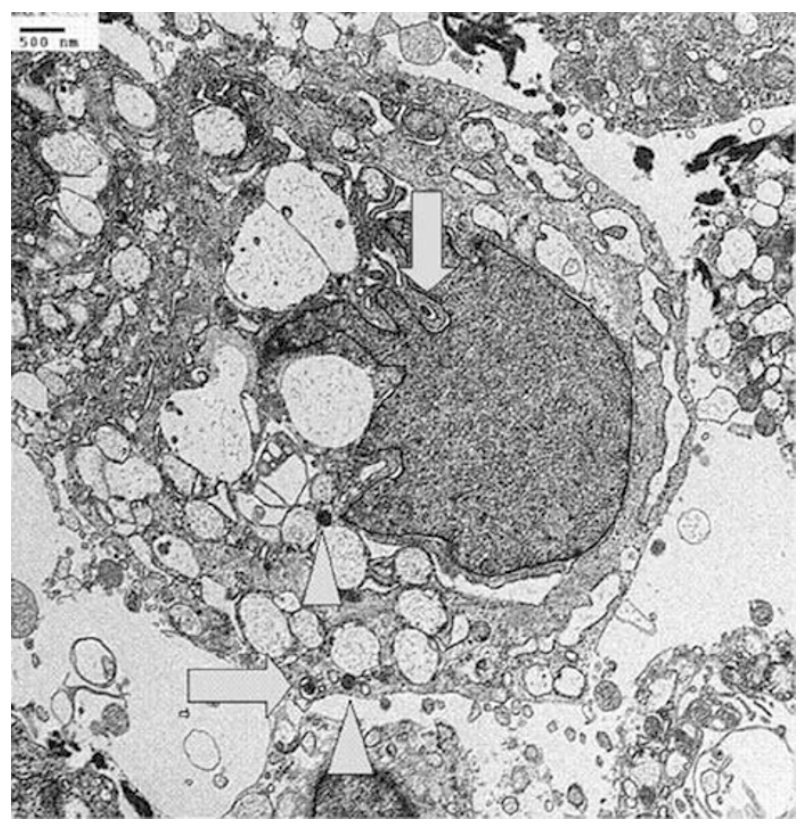

Figure 5 Case 26: Transmission electron micrograph showing nucleocapsids (arrowheads) and enveloped particles (arrows) in the cytoplasm and plasma membrane. 
present in these cases and the virus might have exacerbated this early dysfunction. Some viruses are known to infect sebaceous glands: ${ }^{11-15}$ herpes virus, ${ }^{12,15}$ murine leukemia virus, ${ }^{11}$ and papillomaviruses. ${ }^{13}$ A large percentage of subjects with sebaceous carcinoma of the skin or the eyelid had detectable infection with papillomavirus. ${ }^{13,14}$ The clinicopathologic findings of herpetic conjunctivitis in Case 19, other DNA viruses in Cases 24 and 25 support viral involvement in some chalazia. Prior systemic virus infection, spread of chalazia in families, or recurrent viral keratitis (EpsteinBarr virus, adenovirus, herpes simplex virus) in the present study provide some indirect evidence to a virus aetiology in some chalazia.

The treatment of chalazia is conservative as $80 \%$ resolve with lid hygiene, warm compress, and gentle lid massage. ${ }^{1,7-9}$ Topical broad-spectrum antibiotics are also recommended in some difficult cases. Excision is indicated in nonresolving large chalazia. Intralesional steroids have been advocated in recurrent chalazia, chalazia at the lid margin or near the lacrimal punta, ${ }^{3,16}$ and in children. ${ }^{2}$ Complications of intralesional steroids have included skin depigmentation, ${ }^{3}$ atrophy of dermis and fat, ${ }^{16}$ ocular hypertension, and reactivation of herpetic keratitis. ${ }^{17}$ Treatment of chalazia related to viral conjunctivitis is also conservative, but may require using antiviral or antibiotic medications in specific cases. Based on the present findings, intralesional corticosteroids should be used with great caution in virus-induced chalazia.

\section{References}

1 Bron AJ, Benjamin L, Snibson GR. Meibomian gland disease. Classification and grading of lid changes. Eye 1991; 5: 395-411.

2 Mustafa TA, Oriafage IH. Three methods of treatment of chalazia in children. Saudi Med J 2001; 22: 968-972.
3 Ho SY, Lai JS. Subcutaneous steroid injection as treatment for chalazion: prospective case series. Hong Kong Med J 2002; 8: 18-20.

4 Sirigu P, Shen R-L, Pinto da Silva P. Human meibomian glands: the ultrastructure of acinar cells as viewed by thin section and freeze-fracture transmission electron microscopies. Invest Ophthalmol Vis Sci 1992; 33: 2284-2292.

5 Gutgesell VJ, Stern GA, Hood CI. Histopathology of meibomian gland dysfunction. Am J Ophthalmol 1982; 94: 383-387.

6 Mansour AM. New mechanism of meibomian gland secretion. Orbit 1988; 7: 201-209.

7 Perry HD, Serniuk RA. Conservative treatment of chalazia. Ophthalmology 1980; 87: 218-221.

8 Driver PJ, Lemp MA. Meibomian gland dysfunction. Surv Ophthalmol 1996; 40: 343-367.

9 McCulley JP, Sciallis GF. Meibomian keratoconjunctivitis. Am J Ophthalmol 1977; 84: 788-793.

10 Scobee RG. The role of the meibomian glands in recurrent conjunctivitis. A review with experimental observations. Am J Ophthalmol 1942; 25: 184-192.

11 Churchwell MA, Noah PW, Rosenberg EW, Bale G, Brown PS, Pitcock JA et al. Electron microscopic detection of virus particles in the rhino mouse. Am J Med Sci 1986; 291: 314-320.

12 Clements GB, Jamieson FE. Reactivation of latent herpes simplex virus-1 (HSV) from mouse footpad cells demonstrated by in situ hybridization. Arch Virol 1989; 104: 95-106.

13 Gonzalez-Fernandez F, Kaltreider SA, Patnaik BD, Retief JD, Bao Y, Newman $S$ et al. Sebaceous carcinoma. Tumor progression through inactivation of p53. Ophthalmology 1998; 105: 497-506.

14 Hayashi N, Furihata M, Ohtsuki Y, Ueno H. Search for accumulation of $\mathrm{p} 53$ protein and detection of human papillomavirus genomes in sebaceous gland carcinoma of the eyelid. Virchows Arch 1994; 424: 503-509.

15 Moriyama K, Imayama S, Mohri S, Kurata T, Mori R. Localization of herpes simplex virus type 1 in sebaceous glands of mice. Arch Virol 1992; 123: 13-27.

16 Pizzarello LD, Jakobiec FA, Hofeldt AJ, Podolsky MM, Silvers DN. Intralesional corticosteroid therapy of chalazia. Am J Ophthalmol 1978; 85: 818-821.

17 Kibrick S, Takahashi GH, Leibowitz HM, Laibson PR. Local corticosteroid therapy and reactivation of herpetic keratitis. Arch Ophthalmol 1971; 86: 694-698. 